\title{
Latin-American experience in cryoablation of paroxysmal and persistent atrial fibrillation using second generation cryo-balloon. Acute success and 12 months of follow-up
}

\author{
Experiencia latinoamericana en crioablación de fibrilación auricular paroxística y \\ persistente con criobalón de segunda generación. Resultados en agudo y a 12 meses
}

\author{
Fernando Scazzuso ${ }^{1}$, José L. González², Gerardo Rodríguez³ , Pío Coria-Sandoval", \\ Juan Camargo-Ballestas ${ }^{5}$, Mauricio Moreno ${ }^{6}$, Theodore Merriam ${ }^{7}$, Lauren Hemingway ${ }^{7}$, and Claudio Muratore ${ }^{8 *}$ \\ ${ }^{1}$ Instituto Cardiovascular de Buenos Aires, Buenos Aires, Argentina; ${ }^{2}$ Hospital Universitario Fundación Favaloro, Buenos Aires, Argentina; ${ }^{3} \mathrm{Hospital}$ \\ San Ángel Inn Universidad, Mexico City, Mexico; ${ }^{4}$ Centro Médico Nacional Siglo XXI, Mexico City, Mexico; ${ }^{5}$ Fundación Clínica Shaio, Bogota, \\ Colombia; ${ }^{6}$ Clínica Dávila, Santiago, Chile; ${ }^{7}$ Medtronic Inc, Minneapolis, MN, United States of America; ${ }^{8}$ Medtronic Latam, Buenos Aires, Argentina
}

\begin{abstract}
Objective: Catheter ablation has become a usual technique to treat atrial fibrillation (AF). Medium-term results of prospective and multicenter data concerning pulmonary veins cryoablation in Latin America are limited. The objective is to assess the safety and efficacy of ablation by second generation cryoballoon in patients with paroxysmal atrial fibrillation (PAF) or persistent atrial fibrillation (PerAF) in Latin America. Method: We evaluate the characteristics of the procedure and the acute and 12-month results. Inclusion criteria include patients over 18 years old with AF who have a planned procedure of pulmonary veins isolation with second generation cryoballoon. Treatment failure was defined as any episode of AF, atrial flutter or atrial tachycardia greater than 30 seconds outside the 90-day blinded period. Results: A total of 218 patients (57 \pm 11 years, $66.5 \%$ men, CHA2DS2-VASc $1.2 \pm 1.1$ ) were included in the study. Of these, $83.9 \%$ evidenced PAF, $12.8 \%$ PerAF, and $2.3 \%$ long-standing PerAF. Fifteen with history of atrial flutter. Most patients had failed at least one antiarrhythmic drug (89.4\%). The acute success of the procedure was obtained in 211 patients (96.8\%). The average procedure time was $73.2 \pm 26.7$ min, the fluoroscopy time was $21.4 \pm 23.9 \mathrm{~min}$, and the total lab occupancy time was $114.6 \pm 41.3 \mathrm{~min}$. During the 12-month foIlow-up, freedom from AF recurrence was $88.6 \%$ in PAF, and $73.1 \%$ in PerAF. Twenty-one patients experienced device or procedure-related complications (9.6\%). Conclusions: These results support pulmonary veins electrical isolation with cryoballoon as an effective treatment for AF in Latin America.
\end{abstract}

Key words: Cryoablation. Atrial fibrillation. Pulmonary veins.

\section{Resumen}

Objetivo: La ablación por catéteres es una técnica habitual para tratar la fibrilación auricular (FA). Son escasos los datos prospectivos y multicéntricos con resultados a mediano plazo de la crioablación de venas pulmonares en América Latina. El objetivo es evaluar la seguridad y la eficacia de la ablación por criobalón de segunda generación en pacientes con FA pa-

Correspondence:

${ }^{*}$ Claudio Muratore

E-mail: cmuratore@intramed.net
Date of reception: 24-06-2020

Date of acceptance: $27-08-2020$

DOI: 10.24875/ACME.M21000198
Available online: 19-07-2021

Arch Cardiol Mex (Eng). 2021:91(2):177-182

www.archivoscardiologia.com 2604-7063 / @ 2019 Instituto Nacional de Cardiología Ignacio Chávez. Published by Permanyer. This is an open access article under the CC BY-NC-ND license (http://creativecommons.org/licenses/by-nc-nd/4.0/). 
roxistica o persistente en América Latina. Método: Se evaluaron las características del procedimiento y los resultados en agudo y a 12 meses Se incluyeron pacientes con FA mayores de 18 años a quienes se realizara desconexión de venas pulmonares con criobalón de segunda generación. Se definió como fallo al tratamiento cualquier episodio de FA, aleteo auricular o taquicardia auricular de más de 30 segundos fuera del periodo de cegamiento de 90 días. Resultados: Se incluyeron 218 pacientes (57 \pm 11 años, 66.5\% hombres, CHA2DS2-VASc $1.2 \pm 1.1$ ). Presentaron FA paroxística el 83.9\%, FA persistente el $12.8 \%$ y FA persistente de larga duración el 2.3\%. Quince pacientes presentaban antecedentes de aleteo auricular. Habian fracasado a una droga antiarrítmica el 89.4\%. El éxito en agudo se obtuvo en 211 pacientes (96.8\%). El tiempo promedio del procedimiento fue de $73.2 \pm 26.7$ minutos, el tiempo de fluoroscopia fue de $21.4 \pm 23.9$ minutos y el tiempo total de ocupación del laboratorio fue de $114.6 \pm 41.3$ minutos. Durante los 12 meses de seguimiento, el tiempo libre de recurrencia de FA fue del $88.6 \%$ en FA paroxística y del 73.1\% en FA persistente. Veintiún pacientes (9.6\%) presentaron eventos adversos relacionados con el procedimiento. Conclusiones: Estos resultados indican que la desconexión de venas pulmonares con criobalón es un tratamiento seguro y efectivo para la FA en América Latina.

Palabras clave: Crioablación. Fibrilación auricular. Venas pulmonares.

\section{Introduction}

Atrial fibrillation (AF) is the most common arrhythmia and is associated with increased morbidity and mortality. Catheter ablation of paroxysmal and persistent AF refractory to anti-arrhythmic treatment is an established practice for patients who suffer from it ${ }^{1}$.

Several studies have demonstrated the safety and effectiveness of cryoablation for the disconnection of pulmonary veins in symptomatic patients whom are refractory to anti-arrhythmic drugs ${ }^{2-4}$.

In comparison with radiofrequency ablation, cryoballoon ablation is a technology that employs a simple procedure, with a shorter learning curve $e^{5,6}$, and that has been shown to have comparable results ${ }^{7-9}$. However, currently there is not enough information on the safety and efficacy of AF cryoballoon ablation in Latin America.

This study evaluates the safety and efficacy of paroxysmal and persistent AF cryoballoon ablation with a 1-year follow-up in patients from Latin American centers included in the Cryo AF Global Registry.

\section{Method}

\section{Design}

Cryo AF Global Registry is a prospective, global, multicenter, observational post-marketing study of patients scheduled for AF cryoballoon ablation. The Arctic Front $^{\mathrm{TM}}$ (Medtronic Inc.) cardiac cryoablation catheter systems used in the study are commercially approved. Approximately 100 centers will participate in the global study, enrolling more than 3,500 patients, with six centers belonging to Latin America so far.
This study is carried out in accordance with the international ethical and scientific quality standards known as good clinical practice, and with the ethical standards for experimentation on human subjects established by the Declaration of Helsinki. After approval by the ethics committee of each institution, informed consent is obtained from each patient enrolled in the study.

Between May 2016 and January 2019, 218 cryobalIoon AF ablations were carried out, and all patients completed a 1-year follow-up.

\section{Procedure}

The cryoballoon ablation procedure was carried out in accordance with the usual practice of the participating institution. The goal was electrical disconnection of the four major pulmonary veins or their abnormal equivalents (common ostium, supernumerary veins).

Right femoral vein puncture was carried out under local anesthesia. A decapolar mapping catheter was positioned inside the coronary sinus, and a quadripolar catheter was placed on the upper right vena cava for phrenic nerve stimulation. Prior to trans-septal puncture, heparin was injected as a bolus of $50-100 \mathrm{IU} / \mathrm{kg}$, followed by $1,000 \mathrm{IU} / \mathrm{h}$, adjusted to maintain an activated clotting time of 250-300 seconds during the procedure. After trans-septal puncture was performed, under fluoroscopic guidance and through a deflectable sheath (FlexCath ${ }^{\circledR}$, Medtronic Inc.), a circular mapping catheter (Achieve ${ }^{\circledR}$, Medtronic Inc.) was inserted into each pulmonary vein and the $28-\mathrm{mm}$ balloon was advanced up to each pulmonary vein ostium. All procedures were performed with second-generation cryoballoons. 
Once total occlusion of each pulmonary vein was confirmed by venography, cryoablation was performed with an application of 180/240 seconds, and entrance or exit block was evaluated with the circular mapping catheter. Extra applications and application time were at the discretion of each operator. During each application to the right pulmonary veins, phrenic nerve stimulation was performed. In order to avoid phrenic nerve injury, changes in diaphragmatic contraction were evaluated aided by a hand on the right epigastric region over the diaphragm and, in some cases, fluoroscopy was used to evaluate diaphragmatic contraction.

Acute success was defined as electrical isolation of the pulmonary vein (absence of electrical conduction between the pulmonary vein and the left atrium demonstrated by entrance and exit block confirmation after ablation).

\section{Post-procedure management}

Patients were discharged the day after ablation if their clinical status was stable. After the intervention, patients were telemetrically monitored. Prior to discharge, an electrocardiogram and chest X-ray were performed and, in some patients, an echocardiogram. Oral anticoagulant treatment was restarted the same day of the procedure. Anti-arrhythmic treatment was left at the discretion of the treating physician.

\section{Follow-up}

Standard follow-up was carried out by each participating institution, with a 12-month post-procedure report being mandatory.

All AF, atrial flutter or $>30$-second atrial tachycardia documented episodes were regarded as recurrence. A 3-month blinding period was established for this study.

\section{Objectives}

The primary objectives of the study were: 1) to estimate the absence of atrial fibrillation, atrial flutter or atrial tachycardia recurrence at 12 months, and 2) to estimate adverse events related to the device or cryoablation procedure.

\section{Statistical analysis}

Continuous data are reported as the mean and standard deviation, and categorical data are expressed as numbers and percentages. All baseline information and relevant medical history of all treated subjects are summarized. The Kaplan-Meier method was used to determine 1-year efficacy (freedom from AF at 365 days). A 90-day blinding period was implemented, in which AF recurrences were not regarded as efficacy failure. Recurrences within the blinding period could be managed with standard care, including anti-arrhythmic drugs, cardioversion or ablation repetition. Subjects with recurrence in an annual follow-up visit between 365 and 425 days after ablation were categorized as annual efficacy failure. The analysis was performed using SAS 9.4 (SAS Institute, Cary, NC, USA), except for time-to-event and graphs, which were completed using the survival package on the $R$ statistical software platform, version 3.4.3 (www.r-project.org).

\section{Results}

\section{Baseline characteristics of the population}

Two-hundred eighteen consecutive Latin American patients (mean age of $57 \pm 11$ years, $66.5 \%$ men) with an AF diagnosis who underwent pulmonary veins disconnection with second-generation cryoballoon were included. Among the participants, $83.9 \%$ had paroxysmal $\mathrm{AF}, 12.8 \%$ had persistent $\mathrm{AF}$ and $2.3 \%$ had long-lasting, persistent AF. Baseline characteristics of the study population are presented in table 1. History of hypertension was recorded in $35.8 \%$, and diabetes in $6 \%$. Fifteen patients $(6.9 \%)$, concomitantly, had a history of atrial flutter. Prior to cryoablation, an average of $1.1 \pm 0.6$ anti-arrhythmic drugs for AF prevention had failed. A total of 854 veins were operated on, and no patient was excluded for anatomical reasons observed on pre-procedure CT-scan.

\section{Procedure characteristics}

A 28-mm cryoballoon was used for all patients. In $15(6.9 \%)$, cavotricuspid isthmus radiofrequency ablation was concomitantly performed. Average procedure and fluoroscopy times were $73.2 \pm 26.7$ and $21.4 \pm$ 23.9 minutes, respectively. Procedure time was considered from the puncture to the removal of all patient's catheters. Average total laboratory occupancy time was $114.6 \pm 41.3$ minutes. Acute success of all procedures was achieved in 211 patients (96.8\%). Table 2 shows the details of the procedure. 
Table 1. Baseline characteristics of the population

\begin{tabular}{|l|c|}
\hline Patients & 218 \\
\hline Age (years) & $57 \pm 11$ \\
\hline Male gender & $145(66.5 \%)$ \\
\hline AF onset (years, median, 25-75) & $1.7(0.6-4.3)$ \\
\hline BMI (kg/m $\left.{ }^{2}\right)$ & $28 \pm 4$ \\
\hline Diabetes & $13(6 \%)$ \\
\hline Hypertension & $78(35.8 \%)$ \\
\hline History of atrial flutter & $15(6.9 \%)$ \\
\hline Antiarrhythmic drugs failure & $1.1 \pm 0.6$ \\
\hline Left atrium diameter (mm) & $40 \pm 7$ \\
\hline CHA2DS2VASc & $1.2 \pm 1.1$ \\
\hline
\end{tabular}

AF: atrial fibrillation; BMI: body mass index.

Values are expressed as $\mathrm{n}(\%)$, mean \pm standard deviation or median (range).

\section{Complications}

Twenty-one patients (9.6\%) experienced adverse events related to the procedure or device. Phrenic nerve paresis was confirmed in three cases (1.4\%) during upper right pulmonary vein ablation. Two patients fully recovered at 7 and 50 days of the procedure, while one continues with this complication. In one patient $(0.5 \%)$, mild pericardial effusion was observed, which did not require treatment. One patient $(0.5 \%)$ had an ischemic stroke. One patient $(0.5 \%)$ died during follow-up (sudden cardiac death). One patient $(0.5 \%)$ had a complication at the puncture site (hematoma), which was resolved one week after the procedure (Table 3).

\section{Follow-up}

During a 1-year follow-up, the AF, atrial flutter or atrial tachycardia recurrence-free success rate after a single procedure and a 3-month blinding period was $88.6 \%$ (95\% confidence interval [Cl]: 82.3-92.8) for paroxysmal AF and $73.1 \%(95 \% \mathrm{Cl}: 51.7-86.2)$ for persistent and persistent, long-lasting AF (Fig. 1). Eleven patients underwent ablation repetition outside the blinding period.

\section{Discussion}

This is the first multicenter study to show the results of electrical disconnection and its 1-year follow-up, with second-generation cryoablation balloons in a Latin
Table 2. Data of the procedure

\begin{tabular}{|l|c|}
\hline Energy application & 218 \\
\hline Total number of pulmonary veins treated & 765 \\
\hline Number of applications per vein & $1.2 \pm 0.4$ \\
\hline Average temperature nadir $\left({ }^{\circ} \mathrm{C}\right)$ & $-47.0 \pm 6.6$ \\
\hline Duration (s) & $207.6 \pm 37.8$ \\
\hline Procedure times & \\
\hline Total procedure time (min) & $73.2 \pm 26.7$ \\
\hline Total fluoroscopy time (min) & $21.4 \pm 23.9$ \\
\hline Time inside the left atrium (min) & $47.1 \pm 18.7$ \\
\hline Total laboratory occupancy time & $114.6 \pm 41.3$ \\
\hline
\end{tabular}

Values are expressed as $n(\%)$, mean \pm standard deviation or median (range).

Table 3. Procedure-related complications

\begin{tabular}{|l|c|}
\hline Patients & 218 \\
\hline Complications & $21(9.6 \%)$ \\
\hline Stroke & $1(0.5 \%)$ \\
\hline Phrenic nerve paresis & $3(1.4 \%)$ \\
\hline Hematoma & $1(0.5 \%)$ \\
\hline Sudden cardiac death & $1(0.5 \%)$ \\
\hline Cardiac tamponade & 0 \\
\hline Pericardial effusion & $1(0.5 \%)$ \\
\hline Atrioesophageal fistula & 0 \\
\hline Pulmonary vein stenosis & 0 \\
\hline Other & $14(6.4 \%)$ \\
\hline
\end{tabular}

American population with AF. Based on the data of this study, AF cryoballoon ablation is shown to be a safe and effective procedure in the prevention of AF recurrence, with an acute success rate of $96.8 \%$ and a 1-year atrial tachyarrhythmia recurrence-free rate of $88.6 \%$ in paroxysmal $\mathrm{AF}$ and $73.1 \%$ in persistent $\mathrm{AF}$.

Several studies have exclusively evaluated second-generation cryoballoon efficacy and safety. Chierchia et al. ${ }^{10}$ were the first to report its use for the treatment of paroxysmal $\mathrm{AF}$, with $83 \%$ of patients free of $A F$ recurrence being observed. Several studies with cryoablation in patients with paroxysmal AF show similar results to ours in terms of efectiveness ${ }^{11-13}$.

Regarding effectiveness in persistent $\mathrm{AF}$, our results of atrial tachyarrhythmia recurrence-free patients are also similar to those reported by European multicenter 


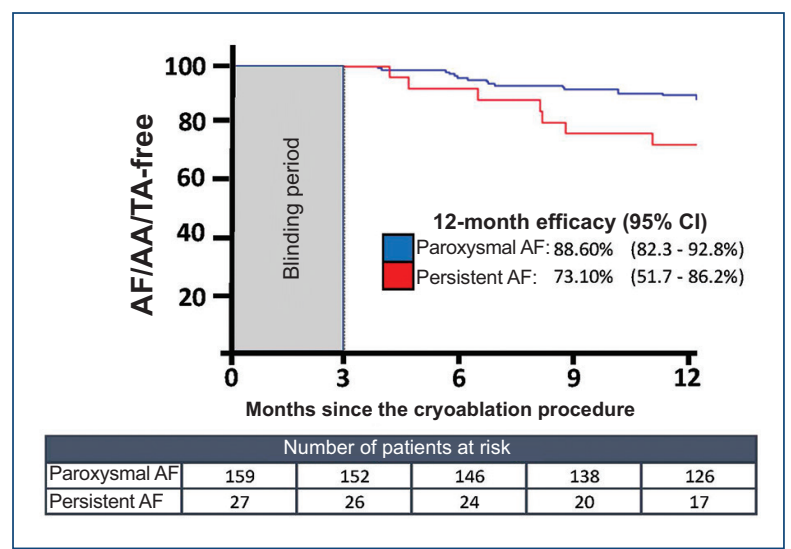

Figure 1. Atrial fibrillation recurrence. Kaplan-Meier curve showing the atrial fibrillation (AF) recurrence-free period during follow-up in patients with paroxysmal $A F$ and persistent AF.

trials $^{14,15}$. It should be noted that there are differences in the number of patients included in these reports, with a lot fewer patients with persistent AF participating in our study in comparison with European registries. On the other hand, in our study, we are considering the persistent AF result in a single group to assess effectiveness, without dividing into persistent and long-lasting, persistent AF.

In the present study, only second-generation cryoballoon was used, which has eight refrigerant ports, unlike the four ports used in the first-generation system. This modification, combined with a $15 \%$ increase in refrigerant flow in the 28-mm cryoballoon, results in more uniform cooling. The results of our study suggest that the new balloon design positively contributes to obtain the desired objective.

While one might expect longer procedural times in operators who are just being started on cryoballon therapy, this is not the case in the Cryo AF Global Registry in Latin America. Total laboratory occupancy time in the STOP AF Pivotal Trial was 371 minutes $^{6}$, while in our study it was 114 minutes. Fluoroscopy time was also shorter in our study compared to STOP AF Pivotal Trial: 21 vs. 63 minutes. In the STOP AF PAS trial ${ }^{13}$, which included 344 patients treated with second-generation cryoballoon, a longer total laboratory occupancy time than in our study was also recorded (231 vs. $114 \mathrm{~min}-$ utes), while fluoroscopy time was similar (20 vs. $21 \mathrm{~min}$ utes). Canpolat et al. ${ }^{16}$ report shorter times for the procedure, 64 minutes, and for fluoroscopy, $12 \mathrm{~min}$ utes. The decrease in fluoroscopy times seems to us to be a relevant data, since they resemble the fluoroscopy times required for radiofrequency ${ }^{7}$. Our results regarding procedure and fluoroscopy times are similar to those published by Ling et al..$^{12}$ and the FIRE and ICE trial?.

The rate of complications reported after pulmonary veins cryoablation using second-generation cryoballoon is highly variable due to the different strategies adopted to calculate these data, such as application of a bonus freeze after the first application, or the strategy based on real-time pulmonary veins potentials disappearance ${ }^{17}$. In our study, total complication rate was $9.6 \%$, which is similar to that reported by Rottner et al. in their study ${ }^{17}$.

The most common complication related to pulmonary veins cryoablation is phrenic nerve palsy/paresis, which often occurs during upper right pulmonary vein cryoablation. In our series, its occurrence was $1.4 \%$, which is lower than that reported in STOP AF PAS and FIRE and ICE, which was $3.2 \%$ and $2.7 \%$, respectively. The lower rate of phrenic nerve paresis in our study could be due to the fact that only a $28-\mathrm{mm}$ balloon was used with fewer applications on the right pulmonary veins and shorter cryoenergy application time, making sure that the balloon was outside the vein and with diaphragmatic contraction adequate and thorough monitoring and phrenic nerve stimulation during right pulmonary veins cryoablation. This complication is known to be benign because it is time-dependent, and to be resolved in most cases before hospital discharge or within the first few months after the procedure. Of the three patients with this complication in our series, two were resolved 7 and 50 days later and one continued with phrenic nerve paresis until the last follow-up.

In our series, pericardial effusion was documented in one patient, but it should be mentioned that he did not require any treatment or hospital stay prolongation. In some publications, this type of complication is not considered if it does not prolong hospitalization. During follow-up, one patient died of sudden cardiac arrest and another had an ischemic stroke.

\section{Limitations}

Our study should be interpreted with some limitations. It is a multicenter, non-randomized, observational study; however, to avoid inclusion biases, all consecutive patients who underwent a second-generation cryoballoon pulmonary vein disconnection procedure were enrolled at each one of the participating institutions. None of the patients was systematically evaluated with 
cardiac tomography to rule out pulmonary vein stenosis, unless they had symptoms in order to rule out said complication. Since effectiveness of the procedure was assessed according to each researcher's usual standard of care, which included 24- or 48-hour Holter, some atrial tachycardia asymptomatic and unsustained episodes may have been lost during follow-up, which would overestimate our result. Future studies with a larger number of patients are needed in order to confirm our results.

\section{Conclusions}

Our multicenter study is the first in Latin America to demonstrate that pulmonary veins ablation with second-generation cryoballoon is safe and effective for the treatment of paroxysmal and persistent AF refractory to antiarrhythmic treatment.

\section{Funding}

This research was sponsored by the Medtronic company. The researchers had the opportunity to review both raw data and statistical data, and the company had no role in the preparation or drafting of the manuscript.

\section{Conflicts of interest}

T. Merrian, L. Hemingway and C. Muratore are Medtronic employees. The rest of the researchers have no conflicts of interest.

\section{Ethical disclosures}

Protection of human and animal subjects. The authors declare that the procedures that were followed adhered to the ethical standards of the responsible committee for experimentation on human beings and were in agreement with the World Medical Association and the Declaration of Helsinki.

Confidentiality of data. The authors declare that they have followed the protocols of their work center on the publication of patient data.

Right to privacy and informed consent. The authors have obtained informed consent from the patients and/or subjects referred to in the article. This document is in the possession of the corresponding author.

\section{References}

1. January CT, Wann LS, Alpert JS, Calkins H, Cigarroa JE, Cleveland JC et al. $2014 \mathrm{AHA} / \mathrm{ACC} / \mathrm{HRS}$ guideline for the management of patients with atrial fibrillation: a report of the American College of Cardiology/American Heart Association Task Force on Practice Guidelines and the Heart Rhythm Society. J Am Coll Cardiol. 2014;64:e1-76.

2. Aryana A, Morkoch S, Bailey S, Lim HW, Sara R, d'Avila A, et al. Acute procedural and cryoballoon characteristics from cryoablation of atrial fibrillation using the first- and second-generation cryoballoon: a retrospective comparative study with follow-up outcomes. J Interv Card Electrophysiol. 2014:41:177-86.

3. Akkaya E, Berkowitsch A, Zaltsberg S, Greiss H, Hamm CW, Sperzel J, et al. Five-year outcome and predictors of success after second-generation cryoballoon ablation for treatment of symptomatic atrial fibrillation. Int J Cardiol. 2018;266:106-11.

4. Su W, Kowal R, Kowalski M, Metzner A, Svinarich JT, Wheelan K, et al. Best practice guide for cryoballoon ablation in atrial fibrillation: the compilation experience of more than 3000 procedures. Heart Rhythm. 2015;12:1658-66.

5. Straube F, Dorwarth U, Ammar-Busch S, Peter T, Noelker G, Massa T, et al. First-line catheter ablation of paroxysmal atrial fibrillation: outcome of radiofrequency vs. cryoballoon pulmonary vein isolation. Europace. 2016;18:368-75

6. Packer DL, Kowal RC, Wheelan KR, Irwin JM, Champagne J, Guerra PG, et al. Cryoballoon ablation of pulmonary veins for paroxysmal atrial fibrillation: first results of the North American Arctic Front (STOP AF) Pivotal Trial. J Am Coll Cardiol. 2013;61:1713-23.

7. Kuck KH, Brugada J, Fürnkranz A, Metzner A, Ouyang F, Chun KR, et al. Cryoballoon or radiofrequency ablation for paroxysmal atrial fibrillation. N Engl J Med. 2016;374:2235-45.

8. Murray MI, Arnold A, Younis M, Varghese S, Zeiher AM. Cryoballoon versus radiofrequency ablation for paroxysmal atrial fibrillation: a meta-analysis of randomized controlled trials. Clin Res Cardiol. 2018;107:658-69.

9. Andrade JG, Champagne J, Dubuc M, Deyell MW, Verma A, Macle L, et al. Cryoballoon or radiofrequency ablation for atrial fibrillation assessed by continuous monitoring: a randomized clinical trial. Circulation. 2019;140:1779-88

10. Chierchia GB, Di Giovanni G, Ciconte G, de Asmundis C, Conte G, Sieira-Moret J, et al. Second-generation cryoballoon ablation for paroxysmal atrial fibrillation: 1-year follow-up. Europace. 2014;16:639-44.

11. De Regibus V, Mugnai G, Moran D, Hünük B, Ströker E, Hacioglu $E$, et al. Second-generation cryoballoon ablation in the setting of lone paroxysmal atrial fibrillation: single procedural outcome at 12 months. J Cardiovasc Electrophysiol. 2016;27:677-82.

12. Ling TY, Jin $Q$, Pan WQ, Zhang N, Lin CJ, Lee HC et al. Cryoballoon ablation in Chinese patients with paroxysmal atrial fibrillation: 1-year follow-up. Pacing Clin Electrophysiol. 2017;40:1067-72.

13. Knight BP, Novak PG, Sangrigoli R, Champagne J, Dubuc M, Adler SW et al. Long-term outcomes after ablation for paroxysmal atrial fibrillation using the second-generation cryoballoon: final results from STOP AF Post-Approval Study. JACC Clin Electrophysiol. 2019;5:306-14.

14. Sawhney V, Schilling RJ, Providencia R, Cadd M, Perera D, Chatha S, et al. Cryoablation for persistent and longstanding persistent atrial fibrillation: results from a multicenter European registry. Europace. 2020;22:375-81.

15. Tondo $C$, lacopino S, Pieragnoli $P$, Molon G, Verlato R, Curnis A, et al. Pulmonary vein isolation cryoablation for patients with persistent and long-standing persistent atrial fibrillation: clinical outcomes from the real-world multicenter observational project. Heart Rhythm. 2018;15:363-8.

16. Canpolat U, Kocyigit D, Yalcin MU, Coteli C, Sener YZ, Oksul M, et al. Long-term outcomes of pulmonary vein isolation using second-generation cryoballoon during atrial fibrillation ablation. Pacing Clin Electrophysiol. 2019;42:910-21.

17. Rottner L, Fink T, Heeger $\mathrm{CH}$, Schlüter M, Goldmann B, Lemes $\mathrm{C}$, et al. Is less more? Impact of different ablation protocols on periprocedural complications in second generation cryoballon based pulmonary vein isolation. Europace. 2018:20:1459-67. 